\title{
The disruption of the rod-derived cone viability gene leads to photoreceptor dysfunction and susceptibility to oxidative stress
}

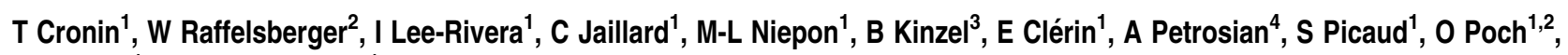 \\ J-A Sahel ${ }^{1}$ and T Léveillard ${ }^{* 1}$
}

Rod-derived cone viability factor (RdCVF) is a thioredoxin-like protein, which has therapeutic potential for rod-cone dystrophies such as retinitis pigmentosa (RP). Cone loss in rodent models of RP is effectively reduced by RdCVF treatment. In this study, we investigate the physiological role of RdCVF in the retina by analyzing the phenotype of the mouse lacking the RdCVF gene, Nxn/1. Although the mice do not show an obvious developmental defect, an age-related reduction of both cone and rod function and a delay in the dark-adaptation of the retina are recorded by electroretinogram (ERG). This functional change is accompanied by a $17 \%$ reduction in cone density and a $20 \%$ reduction in thickness of the outer nuclear layer. The transcriptome of the retina reveals early changes in the expression of genes involved in programmed cell death, stress-response and redox-signaling, which is followed by a generalized injury response with increased microglial activation, GFAP, FGF2 and lipid peroxidation levels. Furthermore, cones of the mice lacking Nxnl1 are more sensitive to oxidative stress with a reduction of $65 \%$ in the cone flicker ERG amplitude measured under hyperoxic conditions. We show here that the RdCVF gene, in addition to therapeutic properties, has an essential role in photoreceptor maintenance and resistance to retinal oxidative stress.

Cell Death and Differentiation (2010) 17, 1199-1210; doi:10.1038/cdd.2010.2; published online 5 February 2010

Retinal degeneration (RD) represents a large group of clinically and genetically heterogeneous blinding diseases within which prospective gene therapies have been studied in depth. $^{1-4}$ One particular form, retinitis pigmentosa (RP) begins with apoptotic death of the rod photoreceptors caused in many cases by mutations in genes expressed specifically by rods followed by the irreversible progressive loss of cone photoreceptors. ${ }^{5}$ The rods, which comprise up to $95 \%$ of the cells in the outer nuclear layer (ONL) of human retina, provide an overwhelming contribution to retinal homeostasis and are thus likely to have a determining role in the fate of the cones. This role is critical as cones mediate vision in lit conditions as well as the visual perception of color and fine-detail and their loss unleashes the most debilitating aspects of blindness. ${ }^{6,7}$ A point of therapeutic intervention after rod demise aimed at preserving cone survival may be sufficient for patient benefit and perhaps optimal, given the range of somatic gene therapies that would otherwise be required. With this objective in mind, the rod-derived cone viability factor (RdCVF) was identified in $2004 .^{8}$ The factor isolated by high content screening protects cones in two rodent models of $\mathrm{RD}$, the rd1 mouse ${ }^{8}$ and the Pro23His rat ${ }^{9}$ and in vitro mediates the resistance to photooxidative damage. ${ }^{10}$

RdCVF corresponds to a truncated thioredoxin (TRX)-like protein and is encoded by the exon 1 of the nucleoredoxin-like
$1(N x n / 1)$ gene. In addition to the RdCVF mRNA, the Nxnl1 gene produces a second mRNA by splicing together exons 1 and 2 to yield a longer protein isoform RdCVFL containing an entire TRX fold. We have also identified $N x n / 2$, a paralogue encoding the RdCVF2 protein. ${ }^{11}$ TRX proteins have an important role in maintaining a reducing environment in the cell. ${ }^{12}$ The diverse integrated TRX functions, which include apoptosis and cell communication, are based on thioloxidoreductase reactions mediated by a conserved CXXC catalytic site within the TRX fold. Disruption of TRXs can thus lead to conditions of oxidative stress. RdCVF does not have any thiol-oxidoreductase activity, however, the production of a second Nxn/1 gene product RdCVFL, corresponding to an active TRX in the 'living fossil', Carcinoscorpius, suggests that the trophic activity is regulated by redox signaling through the mediation of RdCVFL. ${ }^{13}$ Recently, we have shown the participation of RdCVFL in the oxidative stress signaling through its interaction with the microtubule-binding protein TAU. ${ }^{14}$ We show here that the disruption of the Nxn/1 gene leads to a progressive loss of the function and viability of both cone and rod photoreceptors. Furthermore, the sensitivity of the Nxnl1 knockout mice to oxidative stress shows that RdCVF is part of an endogenous redox-based signaling pathway involved in the maintenance of the retina. These observations are made in the Nxn/1-/- mouse, which

\footnotetext{
${ }^{1}$ Department of Genetics, Institut de la Vision, INSERM, UPMC Univ Paris 06, UMR-S 968, CNRS 7210, Paris, France; '²aboratoire de Bioinformatique et Génomique Intégratives, IGBMC, IIlkirch, France; ${ }^{3}$ Novartis Pharma, Basel, Switzerland and ${ }^{4}$ Bunatian Institute of Biochemistry, Yerevan, Armenia

*Corresponding author: T Léveillard, Department of Genetics, Institut de la Vision, INSERM, UPMC Univ Paris 06, UMR-S 968, CNRS 7210, Paris, F-75012 France. Tel: + 331534625 48; Fax: + 331534625 02; E-mail: thierry.leveillard@ inserm.fr

Keywords: injury response; microarray; neuroprotection; retinal degeneration; thioredoxin

Abbreviations: $N x n / 1$, nucleoredoxin-like 1; RdCVF, rod-derived cone viability factor; RP, retinitis pigmentosa; TRX, thioredoxins; FGF2, fibroblast growth factor 2; MAPs, microtubule-associated proteins

Received 06.4.09; revised 03.12.09; accepted 03.12.09; Edited by L Scorrano; published online 05.2.10
} 
nevertheless express the potentially compensatory $N x n / 2$ gene, showing a critical and unique protective role for this gene in the retina.

\section{Results}

Construction of Nxnl1-/- Mouse Strain. Conditional gene targeting was used to create by homologous recombination an embryonic stem (ES) cell line with an allele where loxP sites frame exon 1 of the $N x n / 1$ gene (Figure 1a). ES cells carrying the targeted allele (Figure 1b) were injected into blastocysts and subsequently injected into foster mothers to generate chimeric mice on the nonpigmented $\mathrm{BALB} / \mathrm{c}$ background. Male chimeric mice were crossed with females of a BALB/C Cre-deletor strain. Heterozygote $N x n / 1+/-$ mice were shown to transmit the
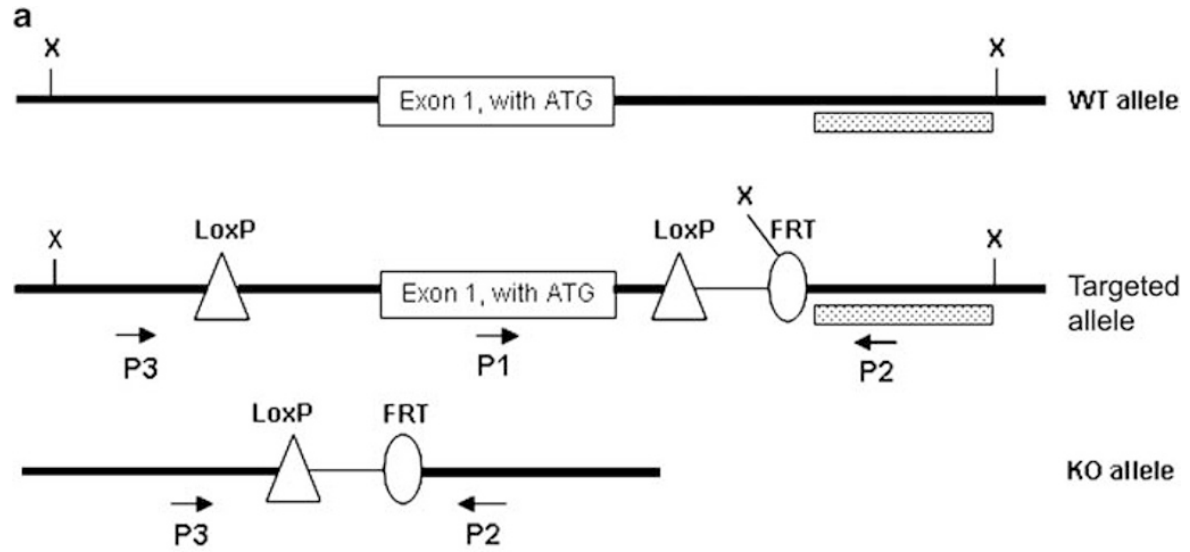

b

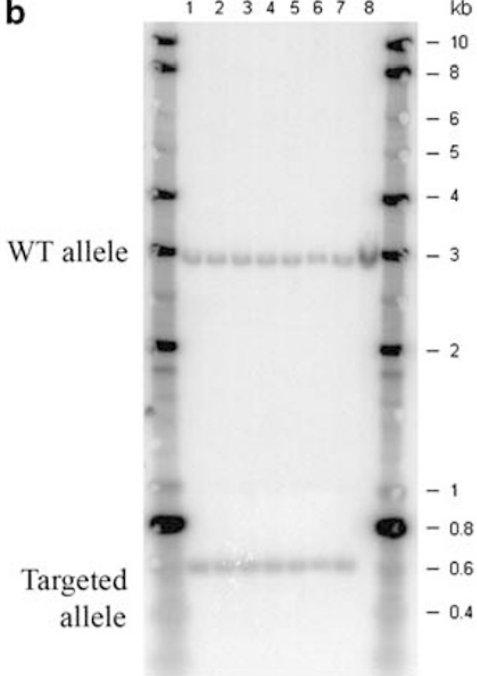

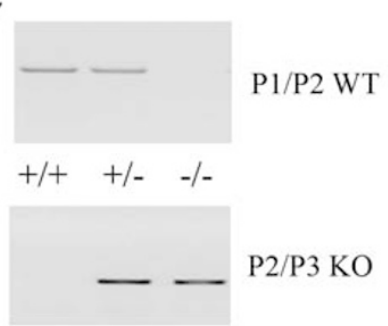

d

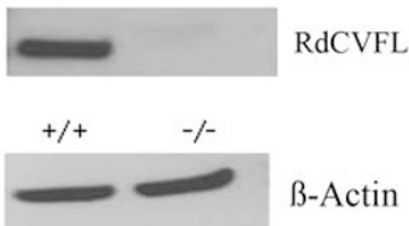

Figure 1 Construction of Nxnl1 knockout mouse. (a) The three constructs presented correspond to the wild-type (WT) Nxnl1 allele, the targeted Nxnl1 allele after homologous recombination and removal of the neomycin selection cassette by Flp-mediated recombination at the FRT sites in ES cells and the targeted Nxnl1 allele after Cre-mediated loxP recombination and deletion of exon1. X: Xba1 restriction sites. Dotted box: probe used for Southern blotting. P1, P2, P3: primers used for PCR genotyping. (b) Southern hybridization with DNA from ES cells. Hybridization was performed with a ${ }^{32}$ P-labeled Nxn/1 probe. Lane 1-7: individual targeted ES clones, lane 8: control DNA from WT ES cells. (c) PCR genotyping of litter mates. The upper panel shows the amplification of exon 1 (P1, P2), absent in homozygote knockout mice. The lower panel shows the amplification using primers (P2, P3) framing exon 1 and resulting in a product that is too large to amplify from WT allele. (d) Western blot showing the absence of RdCVFL protein in Nxnl1-/- retina

Figure 2 Histology and immunostaining of photoreceptors in Nxnl1-/- retinas. (a-d) Flat-mounted retinas were labeled with the cone-specific (PNA) lectin, M-opsin or Sopsin antibodies for automated counting of cone photoreceptor cell density. (a) Representative images of PNA cone-labeling of the retinas used for cone counting. (b) PNAlabeled counts show a $17 \%$ decrease in cell number at 15 weeks of age, $(n=12)$. (c) M-opsin antibody shows a $24 \%$ decrease in M-cone cell number at 15 weeks of age, $P=0.05$, $(n=7)$. (d) S-opsin antibody shows a $39 \%$ decrease in S-cone cell number at 15 weeks of age, $(n=7)$. (e) The outer nuclear layer (ONL) thickness measurements from resin-embedded retinal sections show a $20 \%$ decrease in thickness in the Nxnl1-/- retinas compared with controls at 6 months of age. (f) The thinning of the ONL is linked with age in Nxn/1-/- mice at 3 and 6 months of age. (g) Terminal deoxynucleotidyl transferase dUTP nick end labeling (TUNEL) and 4'-6-diamidino-2-phenylindole (DAPI) images of retinal OCT sections at 3 months. (h) Filter-binding assay showing TAU aggregation. Control: non-pathological human brain extract, AD: Alzheimer's disease human brain extract. (i, j, I, $\mathbf{m})$ Ultrastructure of the outer retina in $N x n / 1+I+(\mathbf{i}, \mathbf{j})$ and $N x n / 1-/-$ mice $(\mathbf{I}, \mathbf{m})$ at $3(\mathbf{i}, \mathbf{I})$ and $12(\mathbf{j}, \mathbf{m})$ months of age. The transmission electron microscopy images show the stacked outer segments of the ONL Scale bar. $5 \mu \mathrm{m}(\mathbf{i}, \mathbf{I})$ as well as the photoreceptor cell bodies of the ONL Scale bar. $2 \mu \mathrm{m}(\mathbf{j}, \mathbf{m})$. (k, $\mathbf{n})$ Immunohistochemistry for RPE65 (green) and recoverin (red) in cryosections of the retinas stained with DAPI (blue) at 18 months of age. OPL: outer plexiform layer, INL: inner nuclear layer. Scale bar: $50 \mu \mathrm{m}$ 
recombinated allele (Figure 1c). From sib-mating the control wild type and the homozygous knockout mice were produced. The absence of expression of RdCVFL, the second product of the $N x n / 1$ gene, was verified by western blot on retinal extracts
(Figure 1d). Protein markers of inner retinal cells and plexiform layers do not show significant differences in levels between wild-type and knockout retinas at 7, 10 and 18 months of age (Supplementary Figures S1a-c).
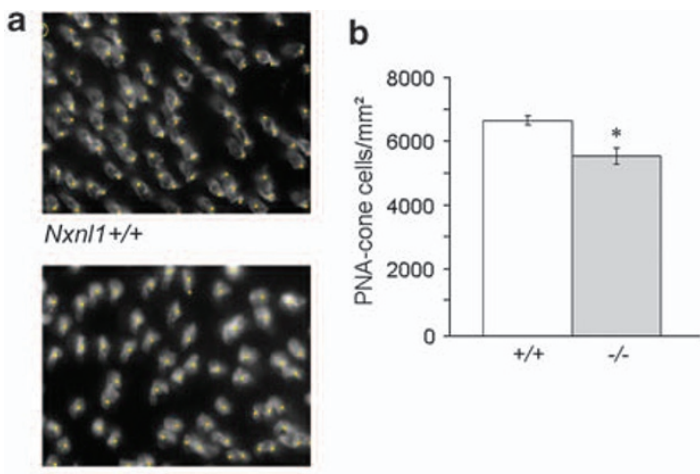

Nxnl1-/-
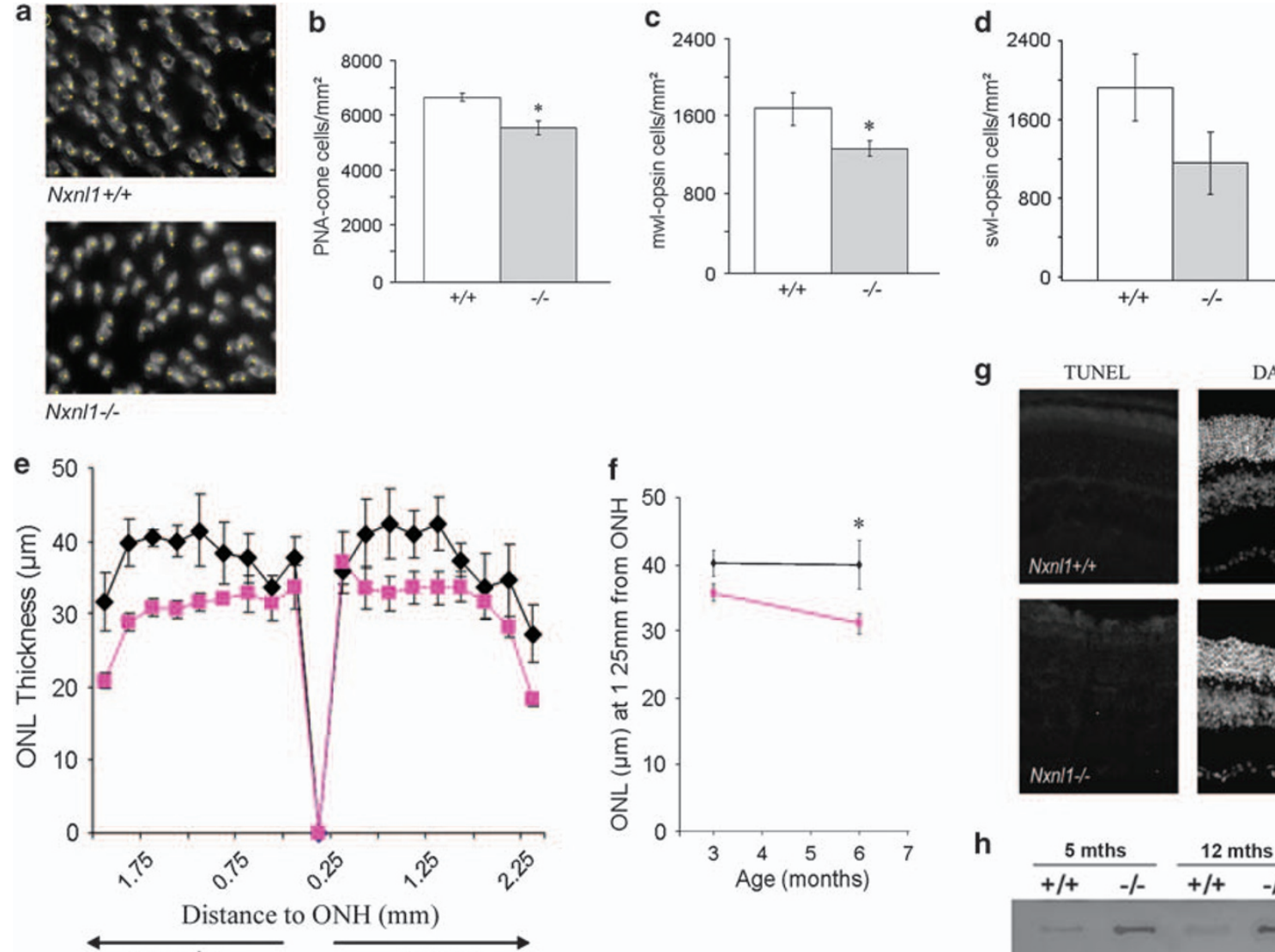

g
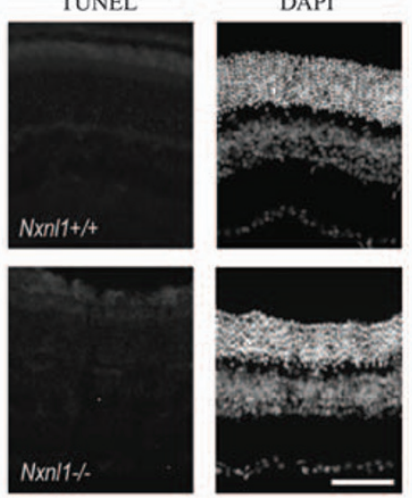

h

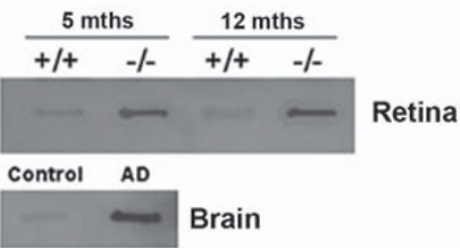

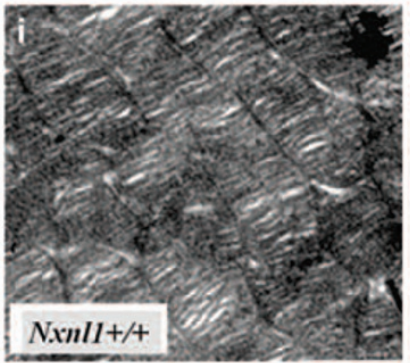
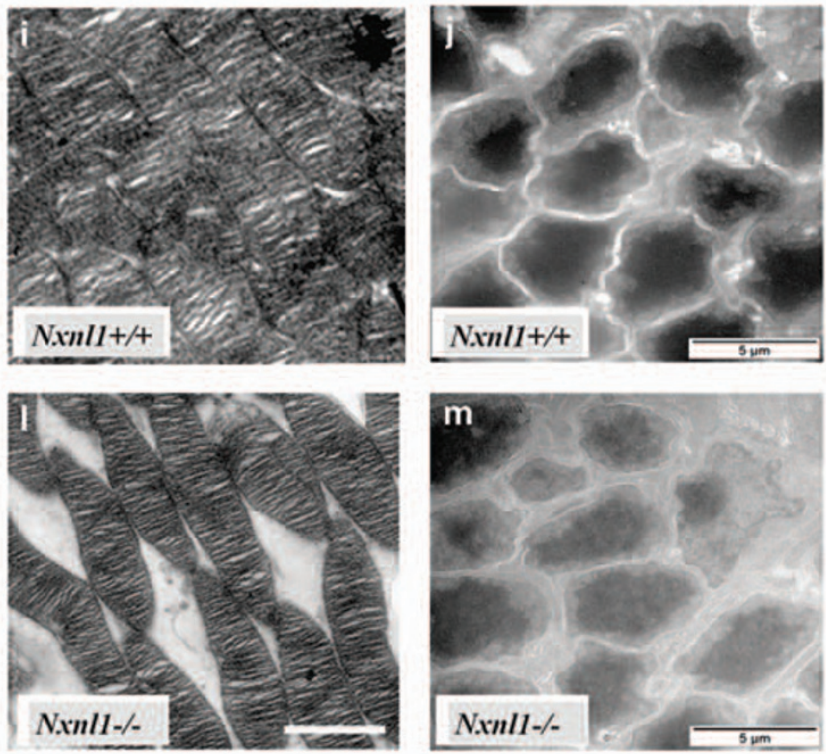

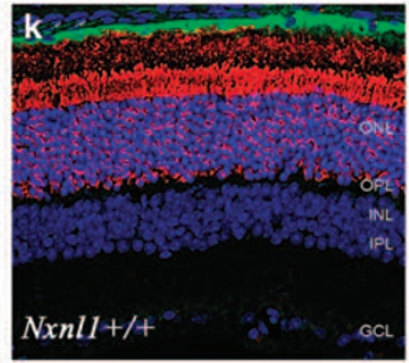

RPE 65

Recoverin

DAPI

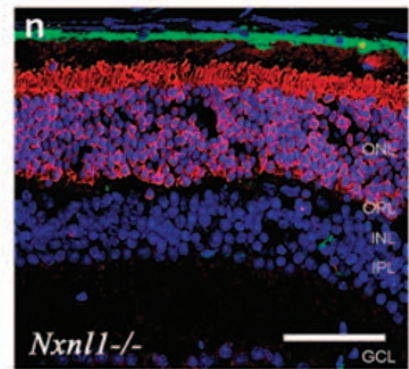


Reduction in Cone Cell Density and Outer Nuclear Thickness in the Nxnl1-/- mouse. The cone cell density in the mice was measured by labeling cones in flat-mounted retinas with the lectin peanut agglutinin (PNA, Figure 2a). A decrease of $17 \%$ in the overall number of cones in the Nxnl1-/- mouse was determined, Nxnl1+/+: $6766+/$ -153; Nxnl1-/-: 5654+/-256, $P=0.008$ (Figure 2b) for mice at 15 weeks of age $(n=12)$. A corresponding reduction was determined in counts when opsin-specific antibodies were used. M-opsin; Nxnl1+/+: 1721+/-310; Nxnl1-/-: $1305+/-125, P \leqslant 0.05$, (Figure 2c), S-opsin: $N x n / 1+/+$ : $1971+/-470 ; \quad N \times n / 1-/-: \quad 1204+/-200, \quad P=0.06$ (Figure 2d).

As the rod photoreceptors comprise more than $95 \%$ of the ONL, the overall thickness of this layer reveals both rod number and integrity. The ONL was found reduced by $20 \%$ in central parts of the superior retina, $P<0.05$ (Figure 2e). This reduction progresses with the age of the animal between 3 and 6 months (Figure 2f) and may be caused by a reduction in cell number and/or their alignment in the ONL. Paradoxically, no TUNEL-positive cells are detected in the 12-month (Figure $2 \mathrm{~g}$ ) or the 3- month-old Nxn/1-/- retina compared with positive controls using $r d 1$ retina (Supplementary Figure S2). However, we found that the Nxn/1-/- retinas contain aggregated TAU protein as measured by filter-binding assay (Figure 2h), as found in the brain of patients suffering from Alzheimer's disease, and in agreement to the interaction of RdCVFL with TAU. ${ }^{14}$ We also observe by electron microscopy that the soma of rod photoreceptor cell bodies is considerably darker in wild type than in the Nxn/1-/- retinas at 12 months of age possibly indicating a vacuolated cytoplasm in the photoreceptors (Figures 2j and $\mathrm{m}$ ). Moreover, significant disruption of outer segments of rods is already evident at 3 months of age (Figures $2 \mathrm{i}$ and I), with an increase of the extracellular space between the segmented stacks. At advanced ages, increased extracellular spaces can also be observed in retinas from 18-month-old Nxn/1-/- mice where nuclear stain DAPI and the ONL marker recoverin are used (Figures $2 \mathrm{k}$ and $\mathrm{n}$ ). The extracellular spaces may represent cell loss and result in the thinning of the ONL as a function of age.

Impaired Vision of the Nxnl1-/- Mouse. The lightadapted electroretinogram (ERG) wave amplitude, reflecting cone function was recorded after $10 \mathrm{~min}$ of light saturation in response to flashes of light intensity of $10 \mathrm{cds} / \mathrm{m}^{2}$. We did not observe any significant differences at 3 months of age between the two genotypes using photopic and flicker ERG (a cone photoreceptor-mediated response examined after $10 \mathrm{~min}$ of $25 \mathrm{cds} / \mathrm{m}^{2}$ light bleach, Figure 3a). A $24 \%$ reduction in amplitude was recorded at 7 months that was further reduced to $32 \%$ at 12 months, $P \leqslant 0.05$ (Figure $3 b$ ). Thus, in accordance with a functional deficit that progresses with age, the cone $b$-wave amplitudes of both the $N x n l 1+I+$ and $N \times n / 1-/-$ decrease as the mice age, but the reduction is more pronounced for the Nxn/1-/- mice and precedes the loss of cone cells.

The rod-mediated responses were recorded at a range of light intensities $\left(0.001-10 \mathrm{cds} / \mathrm{m}^{2}\right)$ after 12-h dark-adaptation. A steady decline in the $N \times n / 1-/-a$ - and $b$-wave amplitudes in all three age groups (3, 7 and 12 months) are observed with increasing light intensity as shown at 3 months (Figure $3 c$ ). The differences in the response were maximal for the mixed $\mathrm{rod} / \mathrm{cone}$ response at a flash intensity of $1 \mathrm{cds} / \mathrm{m}^{2}$. When plotted as a function of age, the a-wave amplitude shows a $26 \%$ reduction at 3 months to $57 \%$ reduction at 12 months, $P=0.007$ (Figure $3 \mathrm{~d}$ ). The $b$-wave amplitudes are proportionally reduced such that the b/a ratios are equivalent for the two genotypes, suggesting that the defect is not located within the inner retinal layer. The maximum voltage responses for the $b$ wave $\left(\mathrm{V}_{\max }\right)$ are listed in Table 1 . As expected, the scotopic trend recorded for the $\mathrm{Nxn} / 1+/+$ mice shows increasing voltage response from 0.001 to $10 \mathrm{cds} / \mathrm{m}^{2}$. This is because time intervals between each scotopic recording are lengthened in proportion with increasing flash intensity allowing the rods to dark-adapt and thus recover function between each flash. In contrast, and as observed at 12 months of age, the $b$-wave amplitude for the Nxn/1-/- mice reaches maximal scotopic response at $0.01 \mathrm{cds} / \mathrm{m}^{2}$ and decreases at higher intensities (Figure $3 e$ ). To analyze this more precisely, we recorded scotopic responses after increasing time intervals of recovery from $5 \mathrm{~min}$ of photo-bleach of $3 \mathrm{cds} / \mathrm{m}^{2}$. In all, 5 to $15 \mathrm{~min}$ of dark-adaptation is required for the $\mathrm{Nxn} / 1-/-$ mouse to recover function and respond to a flash stimulus of $0.1 \mathrm{cds} /$ $\mathrm{m}^{2}$, while the $\mathrm{Nxn} / 1+1+$ mouse has recovered within $2 \mathrm{~min}$ (Figure 3f). Although the parameter $k$ that corresponds to the inverse of the sensitivity of the visual response value did not change significantly across the age groups for the $\mathrm{N} x n / 1+/+$ mice, it did increase significantly in the Nxn/1-/- mice between 3 and 12 months of age from 0.097 to 0.691 $\mathrm{cds} / \mathrm{m}^{2}$ showing an age-related decline in the sensitivity of the rods in the absence of $N \times n / 1$ (Tables 1 and 2).

Differential Gene Expression in the Nxn/1-/- Retina Reveals Early Abnormalities. Microarray profiling of Nxn/1-/- retina at postnatal day 40 (PN40) was performed to identify molecular events that precede the phenotypic changes. Candidate gene expression changes were validated by quantitative RT-PCR (Supplementary Table S1). The largest fold change, aside from the $N x n / 1$ gene itself (named here Txn/6), is for Endothelin 2, (Edn2) with a 35-fold induction in the Nxnl1-/- retina (Supplementary Table S2). Edn2 expression is highly induced in all tested models of photoreceptor disease or injury and points to early abnormalities of the Nxn/1-/- retina. $^{15}$ Stress-activated genes are also induced, such as the crystallins, Gckr linked to metabolic stress and retinol dehydrogenase 9 reflecting possible oxidative stress. We also identified the downregulation of genes of the visual cycle, such as Recoverin (Rcvrn) and Irbp3, in coherence with the delay in dark-adaptation (Figure 3f). In addition, we observed a perturbed expression of genes encoding for cytoskeleton and ciliary proteins.

Injury Response, Microglial-activation and FGF2Signaling in the Nxn/1-/- Retina. Nudix is among the transcripts most significantly induced in the Nxn/1-/- retina (Supplementary Table S2). This natural antisense of the Fgf2 gene is induced in many pathological conditions. ${ }^{16}$ In the retina of the Nxn/1-/- mice at 3 months of age, the 22 and 

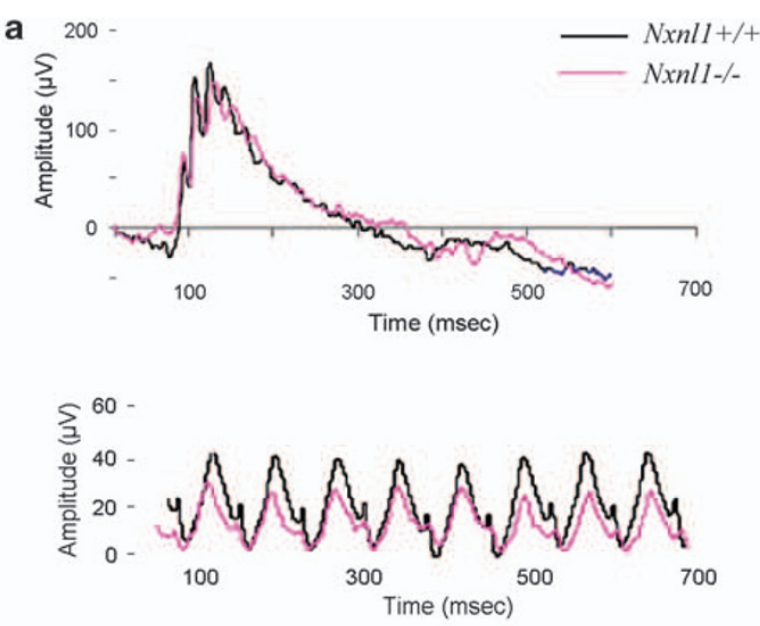
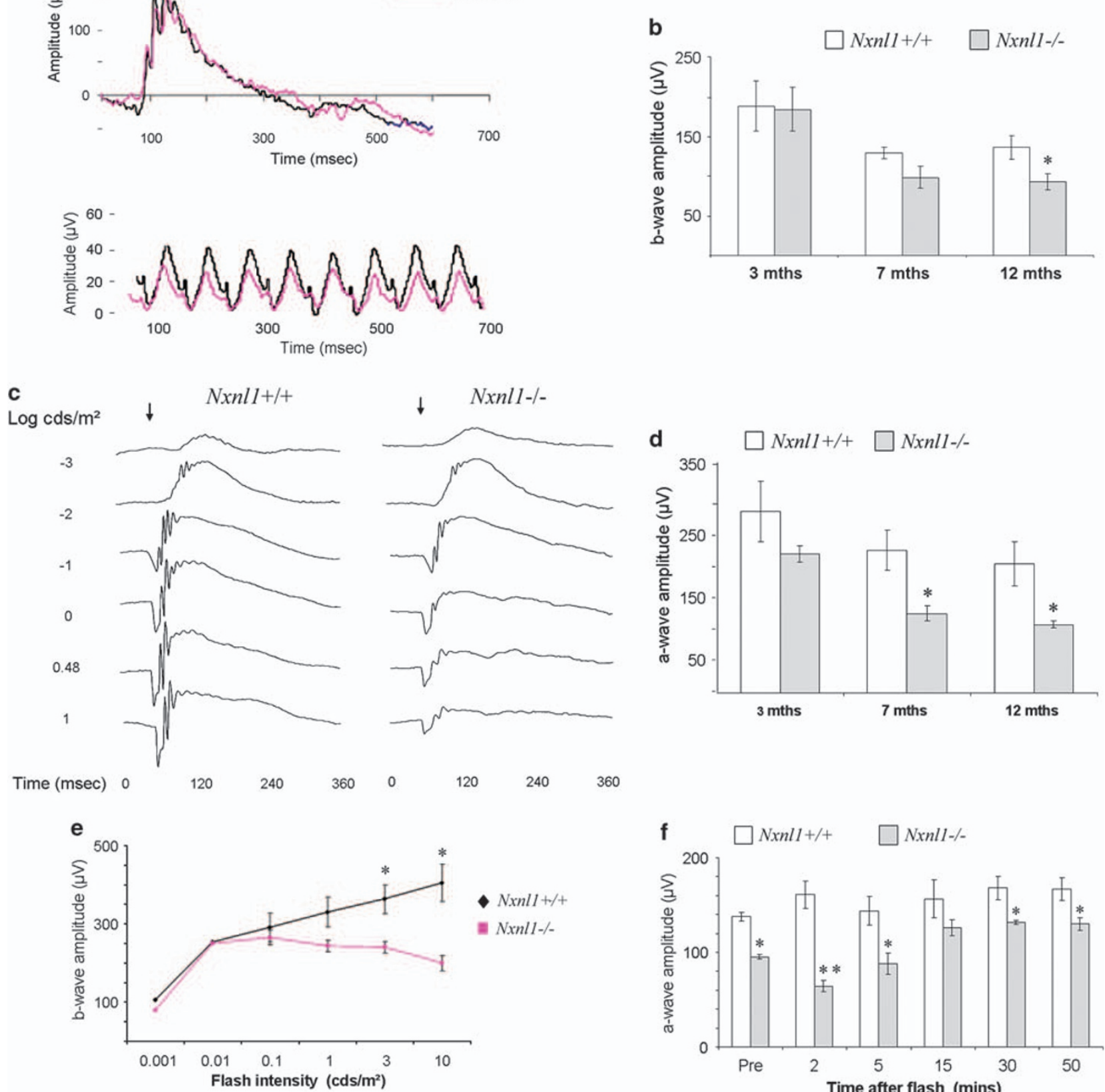
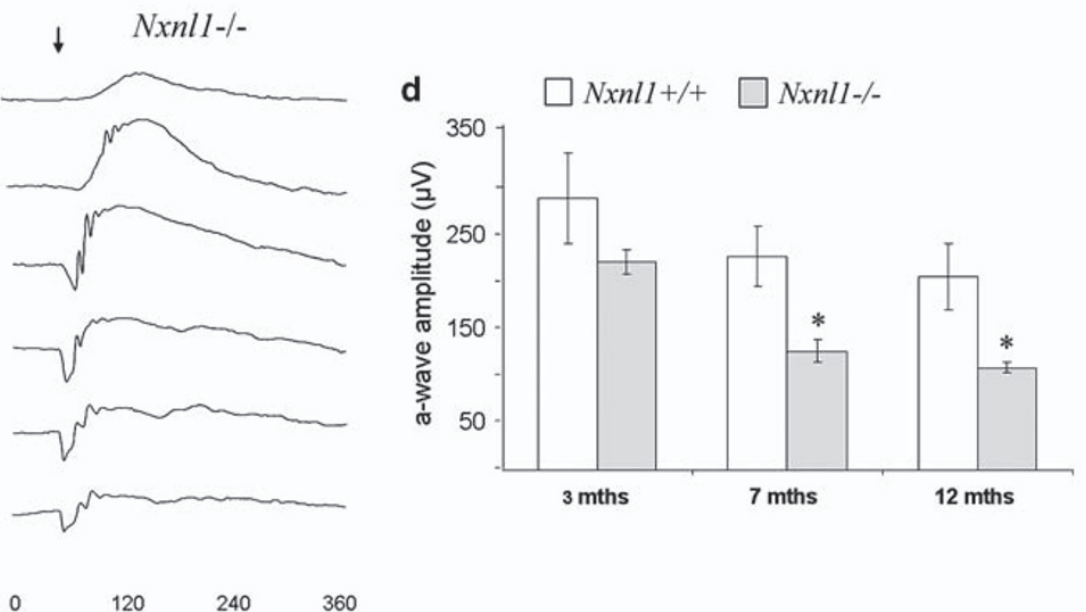

360

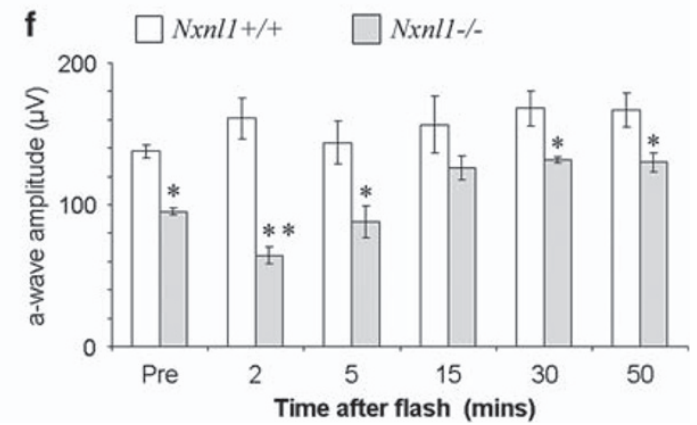

Figure 3 Electroretinography (ERG) of the Nxnl1-/- mice. (a) ERG recordings of photopic (upper panel) and flicker (lower panel) ERGs from Nxnl1 $+/+$ and Nxnl1-/mice at 3 months of age. The 'cone-only' photopic response is obtained using a flash intensity of $10 \mathrm{cds} / \mathrm{m}^{2}$ on light-adapted animals. (b) The absolute amplitudes recorded for the $b$ wave of the photopic ERG ( $n=5$ for each age-group). (c) Representative ERG traces from the scotopic ERGs of Nxn/1 $+/+$ and $N x n / 1-I-$ mice after dark-adaptation overnight. The arrow marks the onset of the flash stimulus. (d) The amplitudes recorded for the a wave in response to flashes of $1 \mathrm{cds} / \mathrm{m}^{2}$ on dark-adapted retinas is shown for three age-groups with a reduction of $57 \%$ in Nxnl1-/- mice at 12 months, ( $n=5$ for each age-group). (e) Voltage-intensity response amplitudes show $b$-wave amplitudes from dark-adapted mice and were used to determine visual sensitivity, $k$ for $N x n / 1+/+$ and $N x n / 1-/-$ mice at 12 months of age. (f) Dark-adaptation analysis for the recovery ERG was carried out on mice at 6 months of age $(n=5), 10 \mathrm{~min}$ after light bleach $\left(3 \mathrm{cds} / \mathrm{m}^{2}\right) \mathrm{Nxn} / 1-/-$ mice have not recovered full a-wave amplitude in response to $0.1 \mathrm{cds} / \mathrm{m}^{2}$ flash stimulus, whereas $N x n / 1+1+$ mice maintain flash response throughout. Error bars show \pm S.E.M., ${ }^{\star} P<0.05,{ }^{\star \star} P<0.01$

22.5-kDa isoforms of FGF2 are more abundant in the total cell extract and the 18-kDa isoform of FGF2 is present at higher levels both in the total extract and in the nuclear fraction (Figure 4a). By 12 months, the level of FGF2 is reduced (Figure $4 \mathrm{~b}$ ). The microglia marker protein IBA-1 is also increased implicating the activation of microglial cells as the source of FGF2 (Figures 4c-d). At 3 months of age, an eightfold increase in microglial cell number in Nxn/1-/- mice was quantified ( $n=4$, Figure $4 c$ ) and was maintained at 12 months of age (Figure 4d). By immunocolocalization, we show that the higher retinal spread of microglial cells is spatially correlated with an increase in FGF2 levels in the 
Table 1 Amplitude of the $b$ wave of the scotopic ERG from $N x n / 1+/+$ and $N x n / 1-/-$ mice

\begin{tabular}{|c|c|c|c|c|c|c|c|c|}
\hline \multirow[b]{2}{*}{ Age } & \multicolumn{2}{|c|}{ b-wave $V \max (\mu \mathrm{V})+I-$ S.E.M. ${ }^{a}$} & \multicolumn{2}{|c|}{ Time to peak (msecs)+/-S.E.M. } & \multicolumn{2}{|c|}{$\mathrm{k}\left(\mathrm{cds} / \mathrm{m}^{2}\right)+I-$ S.E.M. ${ }^{\mathrm{b}}$} & \multicolumn{2}{|c|}{$I_{V \max }\left(c d s / m^{2}\right)^{c}$} \\
\hline & $+/+$ & $-1-$ & $+/+$ & $-I-$ & $+/+$ & $-I-$ & $+/+$ & $-1-$ \\
\hline $\begin{array}{l}3 \text { months }(n=5) \\
7 \text { months }(n=5) \\
12 \text { months }(n=5)\end{array}$ & $\begin{array}{c}568+/-98.0 \\
427+/-60.6 \\
408+/-20.6 \\
\text { At } 7 \text { months } P<0.05 \\
\text { At } 12 \text { months } P<0.01\end{array}$ & $\begin{array}{l}467+/-14.3 \\
315+/-12.7 \\
200+/-19.3\end{array}$ & $\begin{array}{l}49.2+/-5.4 \\
49.4+/-7.3 \\
44.0+/-14\end{array}$ & $\begin{array}{l}32.6+/-2.0 \\
55.4+/-5.2 \\
40.6+/-6.3\end{array}$ & $\begin{array}{l}0.012+/-0.002 \\
0.010+/-0.104 \\
0.006+/-0.009\end{array}$ & $\begin{array}{l}0.097+/-0.12 \\
0.681+/-0.18 \\
0.691+/-0.11\end{array}$ & $\begin{array}{r}10 \\
10 \\
0.1\end{array}$ & $\begin{array}{l}3 \\
0.1 \\
0.1\end{array}$ \\
\hline
\end{tabular}

${ }^{a}$ Maximum ERG voltage for the $b$-wave recorded of flash intensity series in dark-adapted animals. ${ }^{b} k$, flash intensity yielding semi-saturation voltage response. ${ }^{c} / v$ max , flash intensity yielding maximum voltage response. S.E.M.: standard error of the mean.

Table 2 Amplitude of the $b$ wave of the photopic ERG from $N x n / 1+/+$ and $N x n / 1-/-$ mice

\begin{tabular}{|c|c|c|c|c|}
\hline \multirow[b]{2}{*}{ Age } & \multicolumn{2}{|c|}{ b-wave amplitude $(\mu \mathrm{V})+/$ - S.E.M. ${ }^{a}$} & \multicolumn{2}{|c|}{ Time to peak (msecs) +l- S.E.M. } \\
\hline & $+/+$ & $-I-$ & $+/+$ & $-I-$ \\
\hline $\begin{array}{l}3 \text { months }(n=5) \\
7 \text { months }(n=5) \\
12 \text { months }(n=5)\end{array}$ & $\begin{array}{l}188.5+/-31.5 \\
129.2+/-6.9 \\
136.0+/-15.1 \\
\text { At } 12 \text { months } \\
\quad P=0.05\end{array}$ & $\begin{array}{r}184.1+/-27.2 \\
98.2+/-14.0 \\
93.0+/-10.0\end{array}$ & $\begin{array}{l}60.2+/-0.9 \\
68.6+/-12 \\
64.2+/-2.6\end{array}$ & $\begin{array}{l}60.0+/-3.1 \\
65.2+/-2.0 \\
72.5+/-3.3\end{array}$ \\
\hline
\end{tabular}

${ }^{\mathrm{a}} \mathrm{ERG}$ voltage response recorded at $10 \mathrm{cds} / \mathrm{m}^{2}$ from light-adapted mouse retinas.

retina (Figures $4 \mathrm{e}-\mathrm{f}$ ). Such a response is similarly recorded in a number of pathological conditions, including age-related macular degeneration (AMD). ${ }^{17-19}$ This is indicative of an endogenous retinal defense against stress existing in the absence of the $N x n / 1$ gene products arising at an early age. With increasing age this defense may be dampened, as evidenced by declining FGF2 levels (Figure 4b) and microglial infiltration of the ONL (Figure 4d), however, levels remain increased compared with the wild type. It is worth noting that, in addition to secretion of neurotrophic factors, the retinal microglia can trigger inflammation and thus their activation represents a double-edged sword for the survival of neuronal cells. ${ }^{20}$

Lipid peroxidation in Older Nxn/1-/- Retina and Cone Sensitivity to Hyperoxia. In older mice, at 18 months, an accumulating effect of the response to stress is evidenced by the increase expression of glial fibrillary acidic protein (GFAP, Figures 5a-b). A generalized injury response is thus maintained throughout life in the Nxn/1-/- mice.

Among the most toxic products formed because of lipid peroxidation, acrolein and 4-hydroxy-2-nonenal (4-HNE) can modify proteins and inactivate enzymes ${ }^{21}$ and are used as biomarkers of oxidative damage in AMD. ${ }^{22}$ The immunostaining pattern for these adducts was examined in mice at 3 months of age (Supplementary Figure S3) and at 18 months (Figures 5c-d). 4-HNE antibody did not label the Nxn/1+/+ retina but stains the inner retina and photoreceptor cell bodies of the ONL of the $N \times n / 1-/-$ mouse retina with increased intensity at 18 months. We also estimated the level of lipid peroxidation using malondialdehyde (MDA). A 55\% increase in the level of MDA concentration was measured in the $\mathrm{Nxn} / 1-/$ - retina compared with $\mathrm{Nxn} / 1+/+$ at 6 months of age (Figure $5 e$ ), but not at 3 months (not shown). Further- more, brain lysates from these mice did not show any increase in MDA concentration between the two genotypes showing the peroxidation to be specific of the tissue in which $N x n / 1$ is expressed. ${ }^{11}$ Acrolein immunostaining was found more pronounced in the $N x n / 1-/-$ retina at 18 months of age (Figures $5 \mathrm{f}-\mathrm{g}$ ), particularly in regions surrounding cone outer segments (Figures $5 \mathrm{~h}-\mathrm{i}$ ). Similar to $4-\mathrm{HNE}$, the acrolein staining while present in the knockout retina at 3 months (Supplementary Figure S3) was more pronounced at 18 months.

Oxidative Damage to Photoreceptor Proteins Leads to Cellular Dysfunction. Lipid peroxidation alongside the generalized injury response in the $N x n / 1-/-$ retina may arise because of the absence of the TRX enzymatic activity carried by RdCVFL and the consequential changes in the redox environment of the retinal cells. We therefore examine visual function of the $N x n / 1-/-$ mice under oxidative stress conditions, by increasing the oxygen pressure in the retina. ${ }^{23}$ Mice at 3 months of age were caged in a $75 \%$ oxygenenriched environment for 2 weeks, following which retinal function was analyzed. After $12 \mathrm{~h}$ of dark-adaptation, the cone flicker ERG amplitude was recorded and found to be markedly reduced for the $N x n / 1-/-$ mice under hyperoxic compared with normoxic conditions, contrarily to controls (Figures $6 \mathrm{a}-\mathrm{c}$ ). The amplitude is reduced by $60 \%$ for the Nxn/1-/- mice in two separate experiments $(n=10$ for each group). The difference in the amplitudes recorded before hyperoxia was not significant $(33 \mu \mathrm{V}$ for $N x n / 1+/+, 23.7 \mu \mathrm{V}$ Nxn/1-/-, $P=0.2)$. However, the difference becomes significant after hyperoxia $(28 \mu \mathrm{V}$ for $N x n / 1+/+, 10.7 \mu \mathrm{V}$ for $N x n / 1-/-, P<0.01)$. Furthermore, this deficit in cone function is reflected in a $52 \%$ loss of $M$-opsin transcript and a $21 \%$ loss of S-opsin transcripts (Supplementary Table S3). 

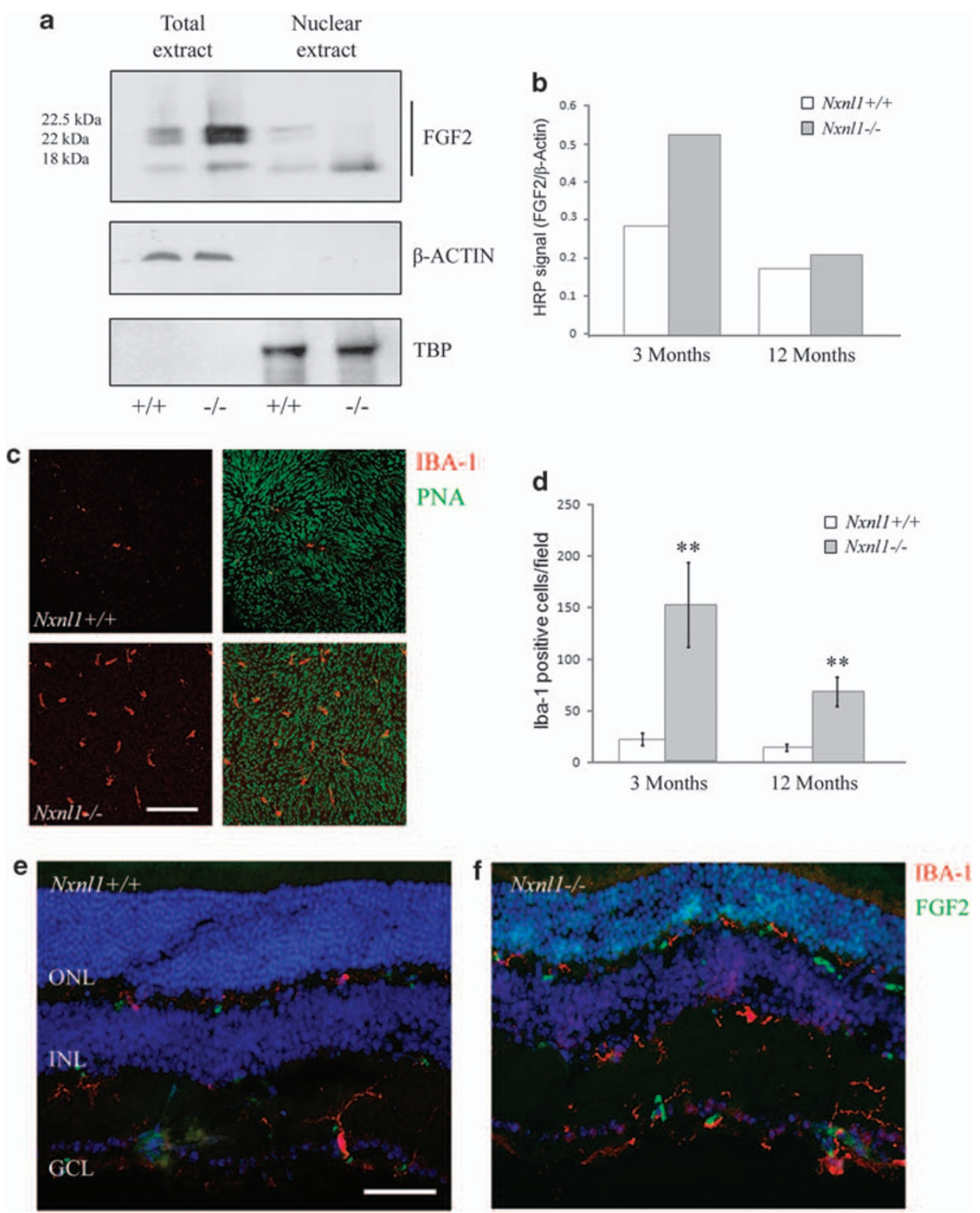

Figure 4 FGF2 and microglial activation. (a) The FGF2 protein levels in total and nuclear extracts from retinas of mice at 3 months of age; the upper panel: FGF2 expression, middle panel: Tata-binding protein (TBP) used as a control for nuclear extracts, lower panel: $\beta$-actin to control for loading of whole cell extracts. (b) Quantification of the FGF2 expression at 3 and 12 months of age (c) Sub-retinal accumulation of microglial cells as revealed by IHC using IBA-1 antibody on flat-mounted retinas from mice at 12 months of age. (d) Quantification of microglial cells using stereological counting of flat-mounted retinas at 3 and 12 months of age. (e, f) Co-immunolabeling of cryosections from retinas of mice at 3 months of age with FGF2 (green) and IBA-1 (red). Error bars show \pm S.E.M., ${ }^{\star \star} P<0.01$

The retinas of BALB/c mice have previously been found to be resistant to the detrimental effects of hyperoxic caging and this resistance is evident for the $N x n l 1+/+$ mice. $^{24}$ In contrast, the cone function of the $N x n / 1-/-$ mice is particularly vulnerable to hyperoxia-induced damage. As under normoxic conditions, TUNEL-positive cells are not detected in the wild-type or the knockout retinas (Supplementary Figure S2) and cannot therefore be correlated with the functional changes. However, a decrease of over $40 \%$ in the expression of the antiapoptotic BCL2 protein is found, in agreement with the decrease in $\mathrm{Bcl} 2$ gene expression detected by microarray (Supplementary Table S2), while the level of pro-apoptotic
BID is increased by over $30 \%$, and BAX over $100 \%$ only in the $N x n / 1+/+$ retina (Figures $6 \mathrm{~d}-\mathrm{e}$ ). It is notable that BCL2 retinal protein levels in the wild type may protect this retina from the damaging effects of hyperoxia (Figures $6 \mathrm{~d}-\mathrm{e}$ ). In contrast, in the knockout the BCL2 levels may not be sufficient to prevent this damage.

\section{Discussion}

We analyze here the role of the retinal-specific trophic factor RdCVF in vivo by analyzing the phenotype of a mouse engineered with a disrupted RdCVF-encoding gene, Nxn/1. The phenotype of the Nxnl1-/- mouse suggests that RdCVF 

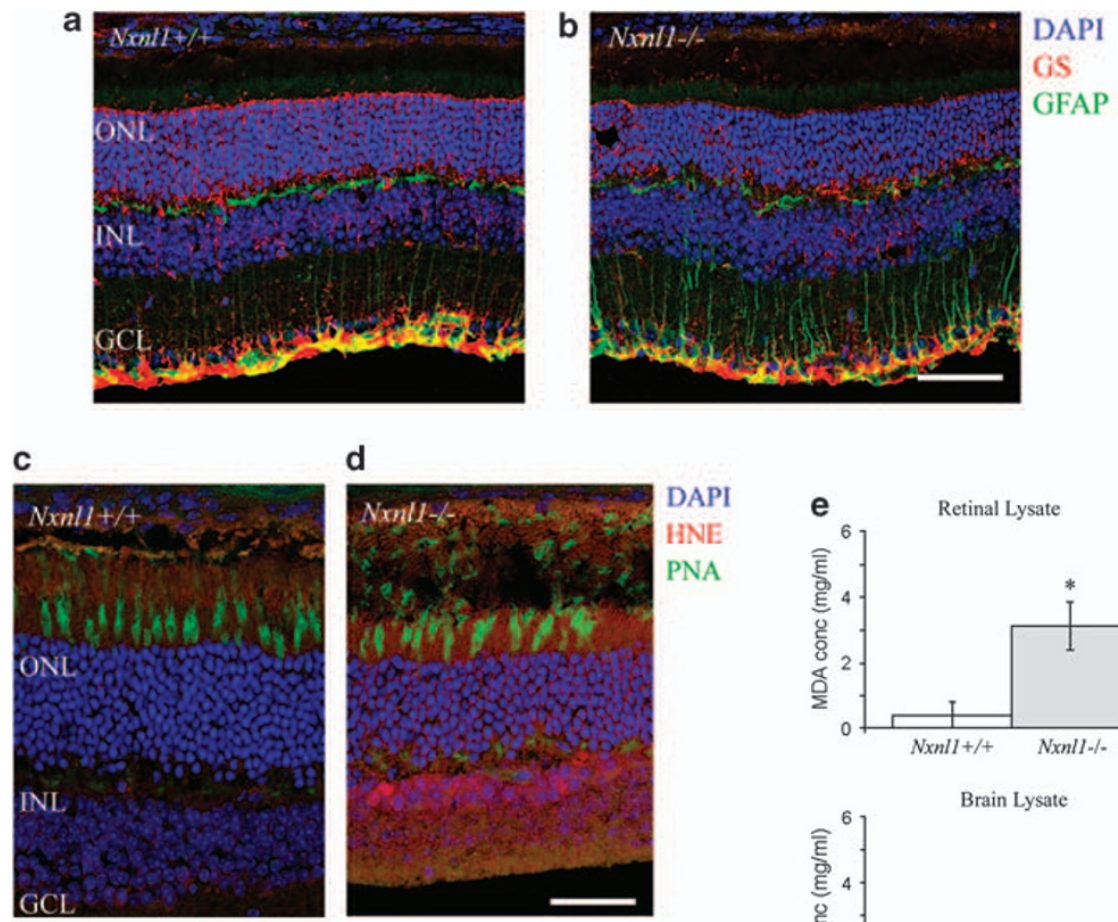

d
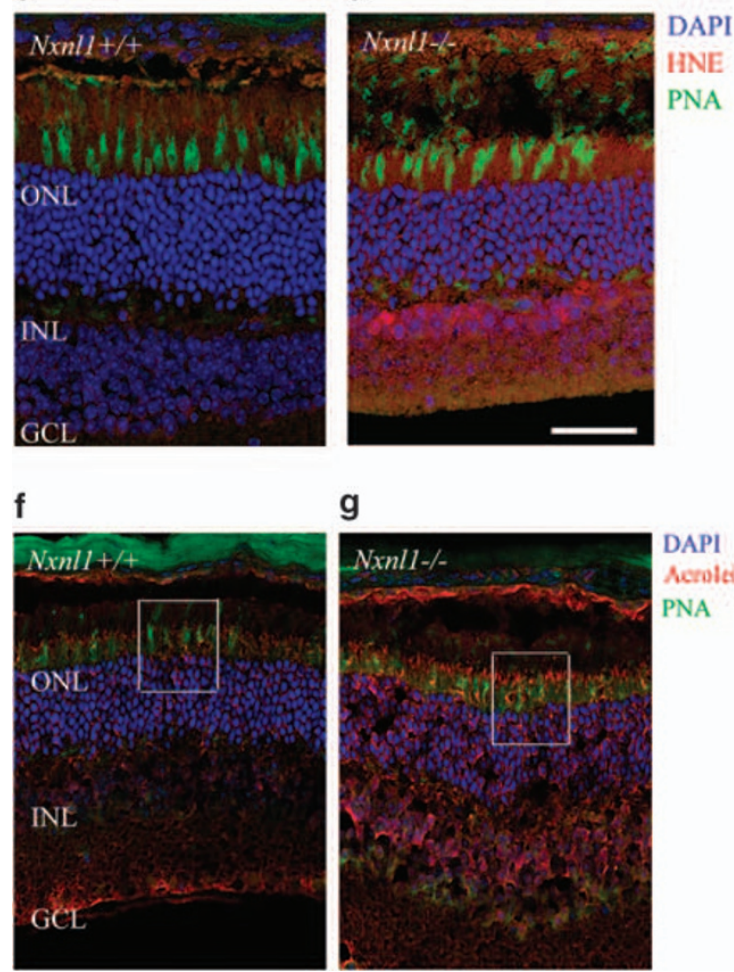

g
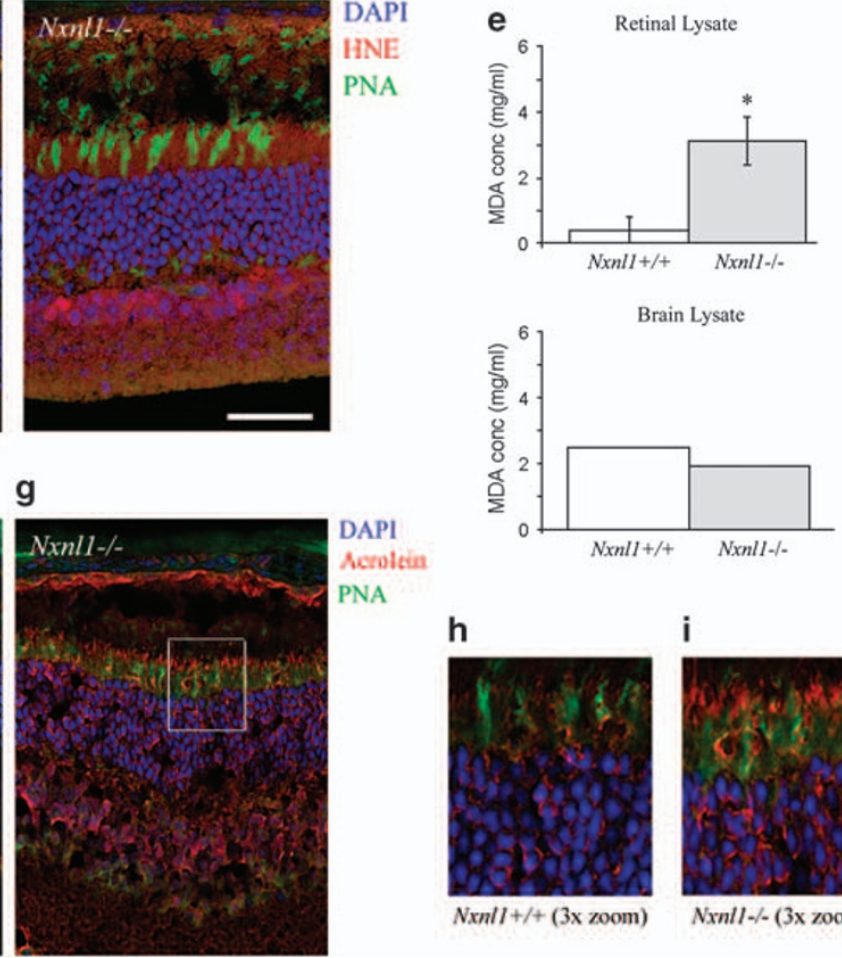

h

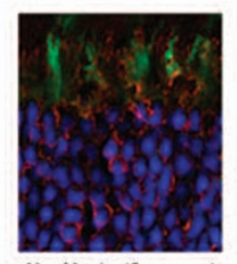

$N x n l l+1+(3 x$ zoom $)$

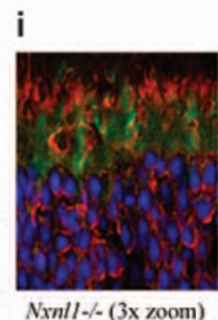

Figure 5 Injury response and lipid peroxidation in aging Nxn/1-/- mice. Immunolabeling of cryosections from retinas of mice at 18 months of age with (a,b) Glial fibrillary acidic protein (GFAP, green) and glutamine synthetase (GS, red) antibodies and (c,d) 4-hydroxynonenal (HNE, red), lectin-PNA (green) and DAPI (blue) (e) Thiobarbituric acid reactive substances (TBARS) assay was used as an index of lipid peroxidation in retinal and brain lysates tested at 6 months of age. (f,g and $\mathbf{h}, \mathbf{i})$ Acrolein (red), lectin-PNA (green) and DAPI (blue) immunostaining on cryosections from mouse retinas. The retinas were sectioned and stained at 18 months of age. Scale bars: a,b: $80 \mu \mathrm{m}$. Scale bars: c,d and f,g : $50 \mu \mathrm{m}$. Scale bars: h,i: $15 \mu \mathrm{m}$. Error bars show \pm S.E.M., ${ }^{\star \star} P<0.01$

does not have an essential role in development with normal formation of the retinal layers (Supplementary Figure S1) and instead has a role in the maintenance of the retina. A homolog of RdCVF termed RdCVF2, encoded by the gene $N x n / 2^{11}$ is predicted to compensate for RdCVF in the Nxn/1-/- mouse retina, however, as we show here this potential compensation is not complete. Changes in the visual phenotype of the model are relatively mild until 6 months, after which the degenerative effects of age are more pronounced in Nxn/1-/- mouse retinas compared with $\mathrm{Nxnl1}+/+$. The delay in visual recovery to dark-adaptation (Figures $3 \mathrm{~d}-\mathrm{f}$ ) possibly indicates a dysfunction of the visual cycle. The described defect in the rods may be attributed to the absence of a paracrine activity from secreted RdCVF or alternatively to the absence of the second isoform encoded by the gene RdCVFL within the rods themselves. ${ }^{14}$ The presence of aggregates of TAU, an RdCVFL interacting protein indicates that the death of photoreceptors in the Nxn/1-/- retina may be triggered by these aggregates, as reported in Alzheimer's disease. ${ }^{25}$ TUNEL-positive cells are not detected, however, this may be explained by the slower rate of degeneration observed here, with $20 \%$ of the cells in the ONL lost over a period of 6 months as compared with the $r d 1$, which looses $97 \%$ of these cells over 15 days (Supplementary Figure S2). The reduced cone number and function (Figures $2 a-d, 3 a-b$ ) is evidence that RdCVF is involved in the viability of these photoreceptors. However, the cone phenotype under normal conditions is milder than that of the rod; as such additional protective pathways are likely to be involved. ${ }^{26}$ Nevertheless, as the cone-specific detrimental effects of hyperoxia in the Nxn/1-/- 


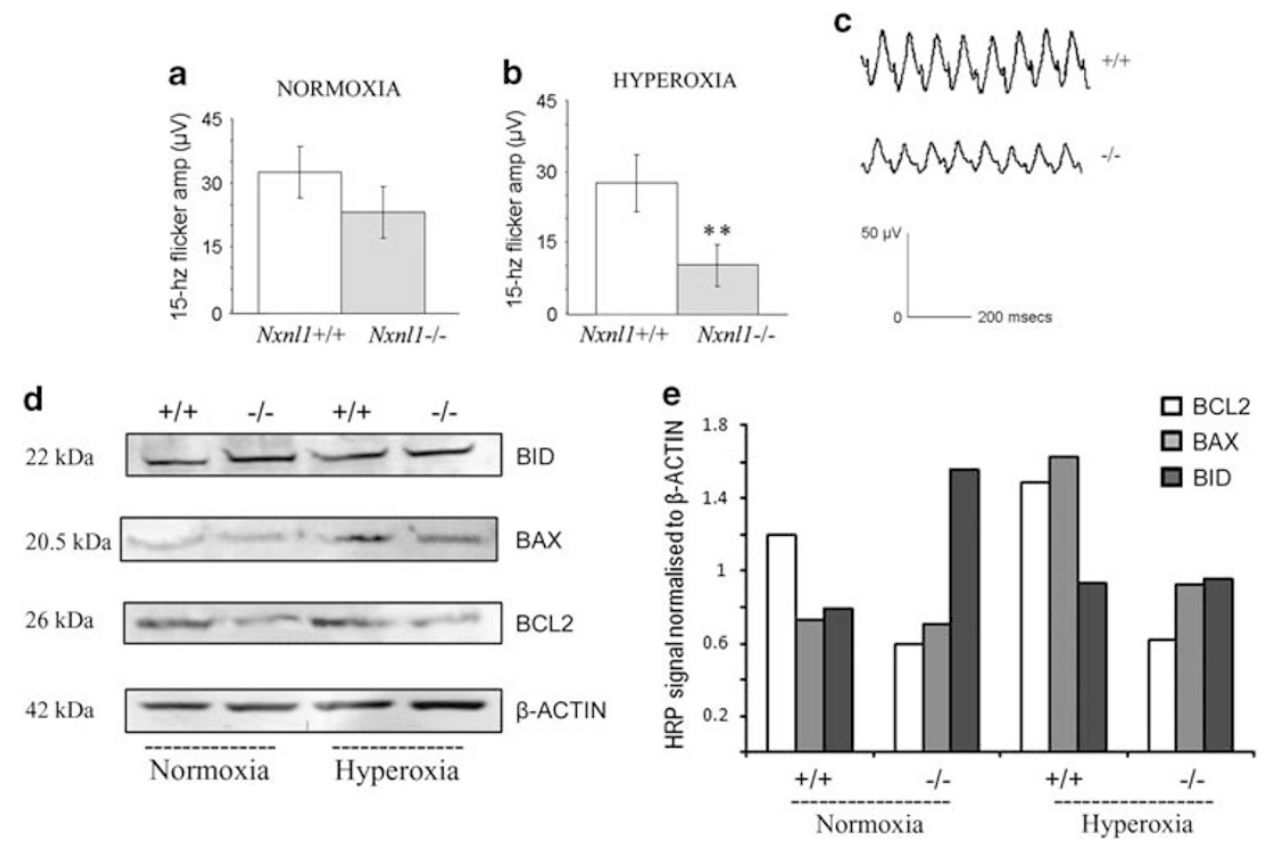

Figure 6 Hyperoxic stress and cell death signaling in Nxnl1-/- mice. (a,b) The amplitude measured for the 15-hz flicker ERG from 3-month-old mice under normoxic and hyperoxic (2-week caging in 75\% ambient oxygen) conditions are shown. Error bars show \pm S.E.M., ${ }^{\star \star} P<0.01$. (c) A representative flicker ERG trace from hyperoxic ERG measurements is shown for Nxnl1 $+1+$ and Nxnl1-l- mice. (d) Western blots for BCL2, BID, BAX and $\beta$-actin proteins in retinal extracts from mice used in hyperoxic experiments. (e) Plot of the enhanced HRP signal from western blots after normalization to $\beta$-actin

mouse retina show, the cone-protective role of this factor appears to be magnified under conditions of stress, as arises during RD.

On the basis of the presence of an entire TRX domain of RdCVFL, we hypothesized that the photoreceptor defects result from oxidative stress in the absence of RdCVFL. To analyze this, we examined the oxidative-stress responses of the Nxn/1-/- mouse and found that the Nxn/1-/- mice show decreased cone function following hyperoxia (Figures $6 a-c)$. This suggests that RdCVF has a role in protection against hyperoxia, of significance given that oxygen toxicity is considered to be a major factor in triggering cone photoreceptor death and thus the onset of severe blindness in the end stages of RP. ${ }^{27}$

However, the mechanism of cell loss itself remains ambiguous with a marked absence of TUNEL-positive cells in the retinas of the knockout mice at 3 and 12 months of age. TUNEL staining, although a classic marker for apoptosis may not be reliable in some forms of RD, as the highly efficient autophagocytic mechanisms inherent to retinal function may achieve a rapid clearance of cell debris with each wave of cell loss. ${ }^{28}$ Apart from the kinetics of rod death, the nuclear fragmentation of the dying cells may never be detectable where autophagy arises in close parallel with apoptosis, as has been described to occur in the rd1 mouse and in models of light damage. ${ }^{29}$ The ultrastructural images here support the possibility that vacuolation and the infiltration of autophagosomes is occurring in the cytoplasm of $N x n / 1-/-$ ONL cells and may explain the absence of TUNEL-positive cells. Furthermore, there are other indications of activity from specific cell-death pathways in the Nxn/1-/- retina. Alterations in the Bcl2-signaling, a pathway associated with developmental cell death, are reflected in decreased levels of anti-apoptotic BCL2 protein (Figures 6d-e) and an imbalance in the overall $\mathrm{BCL} 2 / \mathrm{BAX} / \mathrm{BID}$ ratio. The overexpression of TRX 1 has previously been shown to protect against hyperoxia-induced apoptosis in alveolar cells by the upregulation of BCL2 protein. ${ }^{30}$ The absence of the TRX-like RdCVFL protein in the $N x n / 1-/-$ mouse may lead to a disruption of the Bcl2-signaling pathway and therefore compromise a necessary defense mechanism for the mouse retina under conditions of hyperoxia.

The retinal transcriptome at PN40 reveals early abnormalities that precede phenotypic changes. The genes whose expression level is correlated to the number of copies of the $N x n / 1$ gene are likely to have a direct involvement in $N x n / 1$ signaling. Three major potential pathways were distinguished. The fatty acid transporter genes, Fabp4, the trimethyllysine hydroxylase, Tm/he and the Stearoyl-Coenzyme A desaturase-2, Scd2 show a dose-dependent dowregulation (Table 3, Supplementary Table S2) and are all involved in energy metabolism. Their downregulation is suggestive of metabolic changes at the onset of RD similar to that observed before cone death in the rd1 mouse model. ${ }^{26}$ We also observed a gene dose-dependent reduction of two regulators of the Wnt pathway: Btrc and Porcupine (Porcn), a pathway related to that of nucleoredoxin, the distant homolog of $N x n / 1 .^{31}$ Finally, the Srpk2, Cugbp2, Son and Donson involved in alternative splicing, support the interesting possibility that RdCVF and/or RdCVFL are able to regulate their own relative expression by controlling the expression of specific splicing factors.

From this work, we suggest the rod defect to be specifically linked to the absence of the long isoform RdCVFL and to the resulting loss of the redox regulation of targeted proteins, such 
Table 3 Pathways identified as Nxn/1 dose dependent

\begin{tabular}{lc}
\hline Energy metabolism & \\
The fatty acid transporter genes, Fabp4 & $<$ \\
Trimethyllysine hydroxylase, Tmlhe & $<$ \\
Stearoyl-Coenzyme A desaturase-2, Scd2 & $<$ \\
& \\
Wnt pathway & \\
Btrc & $<$ \\
Porcupine, Porcn & $<$ \\
Alternative splicing & \\
Srpk2 & $<$ \\
Cugbp2 & $<$ \\
Son & $>$ \\
Donson & $>$ \\
\end{tabular}

as TAU. However, we also show that a cone-protective function, which in earlier studies was achieved through delivery of the short isoform RdCVF, 8,9 is absent in the Nxn/1-/- model under conditions of more advanced stress.

\section{Materials and Methods}

Animals. All procedures in this study adhered to the ARVO Statement for the use of Animals in Ophthalmic and Vision Research. Animals were housed under a 12-h light/12-h dark cycle and given ad libitum access to food and water.

$N x n / 1$ genomic sequences corresponding to Nxnl1 5'UTR, exon 1 and intron 1 were amplified from BALB/c mouse genomic DNA and subcloned into a modified targeting vector containing a loxP recombination site as well as an FRT-flanked neomycin cassette. Subcloned sequences were validated by comparison with sequences available from the Mouse Ensembl database (gene ID: ENSMUSG00000034829). Finally, a loxP element was inserted into the $5^{\prime} U T R$ upstream of exon 1, resulting in the plasmid $p N x n / 1$ target. BALB/c mouse ES cell culture was performed with primary $\mathrm{X}$-ray inactivated embryonic fibroblasts derived from DR4 mice. ES cells were transfected by electroporation using $12 \mu \mathrm{g}$ of linearized $\mathrm{pNxn} / 1$ target. Transfected ES cells were selected for neomycin resistance using $0.2 \mathrm{mg} / \mathrm{ml}$ geneticin (Invitrogen, Carlsbad, CA, USA). For positivenegative selection, 10 days after transfection, G418-resistant ES cell clones were isolated and analyzed by polymerase chain reaction (PCR) for homologous recombination and for the presence of the loxP element integrated into the Nxnl1 $5^{\prime}$ UTR. To remove the neomycin selection cassette targeted ES cells were transfected with an Flp expression plasmid. Individual ES cell clones were subsequently screened for neomycin sensitivity. DNA was prepared from selected neomycin-sensitive ES cell clones and analyzed by PCR for the loss of the selection cassette. Southern blotting was performed on $12 \mu \mathrm{g}$ of genomic DNA, digested with 30 units of the Xbal restriction enzyme and separated on a $1 \%$ agarose gel. After denaturation the DNA was blotted on a Hybond $\mathrm{N}+$ membrane (GE Healthcare, Munchen, Germany) followed by UV crosslinking. Hybridization with the ${ }^{32} \mathrm{P}$-labeled DNA probe (Rediprime II Random prime labeling kit, GE Healthcare) was performed in Perfect Plus Hybridization buffer (Sigma, St. Louis, MO, USA) at $65^{\circ} \mathrm{C}$ overnight. After washing of the hybridized membrane, image analysis was performed using a phosphoimager. Targeted BALB/C ES cells were injected into C57BI/6 host blastocysts, which were then transferred into pseudopregnant $\mathrm{CB} 6 \mathrm{~F} 1$ foster mothers. Chimeric offspring were identified by coat pigmentation (white BALB/c on a black C57B//6 background). White offspring indicated the germline transmission of the targeted ES cells and were further analyzed for their correct genotype. To generate Nxn/1 knockout mice, targeted mice were mated with BALB/c Cre deleter females (C-TgN(CMV-Cre)\#Cgn), resulting in Cre-mediated loxP recombination and the excision of the floxed exon 1 of the Nxnl1 gene..$^{32}$ Offspring were analyzed for their genotype by PCR performed on genomic DNA prepared from tail biopsies (primer sequences available on request).

Cone counting. Cone counting was performed on mice at 15 weeks $(n=10)$. The retinas were carefully dissected from surrounding tissue in phosphate-buffered saline $0.01 \mathrm{M}, \mathrm{pH} 7.4$ (PBS) warmed to $37^{\circ} \mathrm{C}$ and transferred to $4 \%$ paraformaldehyde at $4{ }^{\circ} \mathrm{C}$ overnight. The retinas were prepared for staining, as described earlier. ${ }^{33}$ Retinas were labeled using either (FITC)-conjugated PNA lectin from arachis hypogae, PNA (1/40), ${ }^{34}$ a S-opsin antibody at $1 / 400$ or a M-opsinspecific antibody (1/200, Calbiochem, San Diego, CA, USA) at $4^{\circ} \mathrm{C}$. Incubation times were $24 \mathrm{~h}$ for PNA and $48 \mathrm{~h}$ for opsin antibodies. The retinas were then rinsed in PBS, $0.05 \%$ Tween-20 and, in the case of opsin-specific antibodies, incubated with a goat anti-rabbit lgG conjugated to either Alexa TM 594 or 488 at $1 / 500$ for $2 h$ at room temperature. The retinas were whole-mounted photoreceptor side-up in fade-resistant mounting media (Biomedia, Forster City, CA, USA).

Cryosectioning and immunostaining. For cryosections, the eyes were enucleated quickly and immersed in PBS. The center of the cornea was removed to allow penetration of the fixative. The eyes were immersed at $4{ }^{\circ} \mathrm{C}$ overnight in $4 \%$ paraformaldehyde in PBS. The tissues were incubated successively in 10, 20 and $30 \%$ sucrose at $4{ }^{\circ} \mathrm{C}$ for cryoprotection and embedded in O.C.T. cryoembedding media (Sakura Finetek, Gentaur, Belgium). Frozen sections of $10-\mu \mathrm{m}$ thickness were used for immunohistochemistry. Antibodies were diluted in blocking buffer $(5 \%$ BSA in PBS-Tween $0.05 \%$ ), at a concentration of $1 / 250$ for the rhodopsin antibody (Rho-4D2), ${ }^{35} 1 / 100$ for FGF2 (Millipore, Billerica, MA, USA), 1/1000 respectively for recoverin (Millipore), RPE65 (Abcam, Cambridge, UK), GFAP (Dako, Glostrup, Denmark) and Glutamine synthetase (Chemicon, Millipore, MA, USA). A concentration of 1/350 was used for HNE antibody (Calbiochem) and 1/200 for acrolein antibody (Cosmo Bio, Tokyo, Japan). Primary antibodies were incubated overnight at $4{ }^{\circ} \mathrm{C}$. For immunostaining using the acrolein antibody, slides were subjected to antigen retrieval heating-cooling cycles as described previously. ${ }^{36}$ For flat-mounted retinas, an immunostain using IBA1 at 1/300 (Wako Chemicals, Inc., Tokyo, Japan) was used. For each antibody, after washing, sectioned tissues were incubated with a secondary antibody: goat anti-mouse IgG conjugated to either Alexa TM 594 or 488 at $1 / 500$ for $1 \mathrm{~h}$. The nuclear marker $4^{\prime}-6$-diamidino-2phenylindole (DAPI, Sigma, Lyon, France) was added to the incubation solution for sectioned tissues, which were ultimately mounted with fade-resistant mounting media (Biomedia).

TUNEL assay. To detect DNA fragmentation in retinal cells, the $10-\mu \mathrm{m}$ cryosections from mice retinas were treated with an in situ cell death detection kit (Roche, Indianapolis, IN, USA) using the TUNEL technique according to the manufacturer's instructions.

Filter-binding assay. Retinal extracts were made in lysis buffer $(10 \mathrm{mM}$ Tris $\mathrm{HCl}, \mathrm{pH} 8.0,150 \mathrm{mM} \mathrm{NaCl}, 1 \mathrm{mM}$ EDTA, 1\% NP40, 1\% sodium deoxycholate), sonicated and suspended in PBS $2 \%$ SDS. In all, $50 \mu \mathrm{g}$ of protein was filtered through $0.22 \mu \mathrm{m}$ nitrocellulose membrane using biodot microfiltration apparatus (Bio-Rad, Hertfordshire, UK) as described. ${ }^{37}$ The membrane was probed with the anti-TAU5 antibody (Abcam, 1/500).

Semithin sectioning and ONL measurement. Mice were anesthetized by a mixture of ketamine $(160 \mathrm{mg} / \mathrm{kg}) / x y l a z i n e ~(32 \mathrm{mg} / \mathrm{kg})$ followed immediately by vascular perfusion of glutharaldehyde $2.5 \%$ and formaldehyde $2 \%$ in PBS. The eyes were embedded in epoxy resin and histological sections of $1-\mu \mathrm{m}$ thick were made along the sagital axis at the optic nerve level as previously described. ${ }^{38}$ Briefly, in each of the superior (dorsal) and inferior (ventral) hemispheres, ONL thickness was measured in nine sets of three measurements each (total of 27 measurements in each hemisphere). Each set was centered on adjacent $250-\mu \mathrm{m}$ lengths of the retina, with the first set centered $250 \mu \mathrm{m}$ from the optic nerve head and subsequent sets located more peripherally. Within each $250-\mu \mathrm{m}$ length, the three measurements were made at defined points separated from one another by $50 \mu \mathrm{m}$. The 54 measurements in the two hemispheres sampled are representative of the entire retina.

Transmission electron microscopy. The eye cups were fixed in $2.5 \%$ glutharaldehyde at room temperature $2 \mathrm{~h}$, extensively washed overnight and post-fixed in osmium tetraoxide $1 \%$ for $1 \mathrm{~h}$ at room temperature. Samples were washed in Ringer-Krebs Buffer ( $140 \mathrm{mM} \mathrm{NaCl} ; 4.5 \mathrm{mM} \mathrm{KCl}, 2.2 \mathrm{mM} \mathrm{CaCl}_{2}, 12 \mathrm{mM}$ $\mathrm{MgSO}_{4}, 12 \mathrm{mM} \mathrm{NaHCO}_{3}, 0.44 \mathrm{mM} \mathrm{KH}_{2} \mathrm{PO}_{4}, 5.55 \mathrm{mM}$ glucose, pH 7.4) followed by dehydration in graded ethanol and acetone. They were embedded in epoxy resin and ultrathin sections (400 to $600 \mathrm{~nm}$ ) were cut and stained with uranyl acetate and lead citrate and observed under an electron microscope (Met Zeiss 912, Le Pecq, France at $80 \mathrm{kV}$ ). 
Western blotting. Retinas from mice were dissected and homogenized by sonication in RIPA buffer (PBS buffer, 1\% NP-40, 0.5\% sodium deoxycholate, $0.1 \%$ sodium dodecyl sulfate) containing protease inhibitors. Isolation of DNA-binding proteins was achieved using a high-salt extraction protocol as described by Andrews and Faller. ${ }^{39}$ Whole cell extract protein concentrations were measured by Bradford's assay. Nuclear extract protein concentration was measured using the RC-DC protein assay (Bio-Rad, San Diego, CA, USA). In all, $40 \mu \mathrm{g}$ of protein was loaded on a $12 \%$ SDS-PAGE and transferred to nitrocellulose. The membrane was saturated with PBS $1 \mathrm{x}, 0.05 \%$ Tween-20,5\% nonfat dry milk for $1 \mathrm{~h}$ at room temperature and then incubated overnight at $4{ }^{\circ} \mathrm{C}$ with anti-FGF2 $(1 / 1000$, Millipore), anti-BAX (1/1000, Cell Signaling, Danvers, MA, USA, \#2772), anti-BCL2 (1/1000, Abcam, ab18210, Cambridge, MA, USA) or anti-BID (1/800, Millipore AB1730). After washing, the membrane was incubated with peroxidase-conjugated goat anti-rabbit secondary antibody (1/15000, Jackson ImmunoResearch Laboratories, Hamburg, Germany) for $1 \mathrm{~h}$ at room temperature. Antibody binding was revealed by Enhanced Chemiluminescence system and hyperfilm-ECL X-ray film (GE Healthcare, GmbH). To ensure equal loading an antibody-removal was achieved using Reblot recycling kit (Chemicon, Millipore), the membrane was then washed, saturated and subsequently reincubated with monoclonal anti- $\beta$-actin antibody (1/1000, T5168, Sigma) and anti-TBP18 (1/1000, Abcam).

MDA assay. To test for the level of MDA, a product of retinal lipid peroxidation a TBARS assay kit was used (Cayman Chemical Company, Ann Arbor, MI, USA). In all, $25 \mathrm{mg}$ of retinal tissue or brain tissue was sonicated on ice in $250 \mu \mathrm{l}$ of RIPA buffer. Following centrifugation at $1600 \mathrm{~g}$ for $10 \mathrm{~min}$ at $4{ }^{\circ} \mathrm{C}$, the supernatant was stored for use in the assay. The prescribed TBARS protocol was used, in addition to the duplicate pipetting of MDA aliquots of known concentration to produce a standard curve and the triplicate-pipetting of each test sample. The absorbance was read from the 96-well plate at $570 \mathrm{~nm}$ using a plate reader. The averaged values were used to determine MDA concentration from the MDA standard curve graph. TBARS analysis was repeated three times on retinal lysate with $n=3$ mice used in each assay.

RNA purification and gene expression analysis. Animals were killed by cervical dislocation. The eyes were removed, and retinal tissue was dissected free of retinal pigment epithelium (RPE) and placed in guanidine $\mathrm{HCl}$ (Promega, Charbonnières, France). The samples were subsequently disrupted and homogenized using a rotor stator (Polytron PT2100). RNA used for transcriptomic studies was purified from a cesium chloride gradient produced by high-speed ultracentrifugation according to the method of Glisin et al. ${ }^{40}$

Microarray analysis. Using purified retinal RNA from PN40 mice $(n=5)$, cDNA probes were subsequently generated and hybridized to Affymetrix gene chips (mouse genome 4302.0 array, Santa Clara, CA, USA). Three replicates were performed for each experiment. quality control (QC) was performed using RReportGenerator, ${ }^{41}$ and confirmed that all arrays used in the study were of good and consistent quality (available on request). The complete QC report is available on request. Affymetrix raw data were summarized and normalized using gcrma ( $R /$ Bioconductor) and filtered to remove genes with very low signal intensities in all samples. Differential gene expression in the Nxnl1+/- and Nxnl1-/transcriptomes was determined using local false discovery rate (FDR) ${ }^{42}$ The genes resulting from the statistical analysis of $+I+,+I-$ and $-/$ - mice were combined to a single (non-redundant) list and the standardized expression profiles for each probe-set were clustered using DPC. ${ }^{43}$ Out of the resulting clusters only the clusters with progressively decreasing cluster-averages (minimum slope of 1.1) were selected and upregulated or downregulated probe-sets combined. The validity of the clustering results was verified by plotting (i) the cluster-profiles of the original (non-standardized) data and (ii) by projection onto the first and second principal components (data not shown).

\section{Electroretinography}

Handling the mice. After overnight dark-adaptation, animals were prepared for recording under dim red light. After intramuscular anesthesia with a mixture of ketamine $(80 \mathrm{mg} / \mathrm{kg})$ and xylazine $(16 \mathrm{mg} / \mathrm{kg})$ diluted in saline, pupils were dilated by topical application of $1 \%$ atropine sulfate. Upper and lower lids were retracted to keep the eye open and proptosed. Body temperature was maintained at $37^{\circ} \mathrm{C}$ through the use of a circulating hot water heating pad. The electrical signal was recorded using a pair of electrodes constructed specifically for use on mice. A gold loop electrode was placed on the center of the corneal surface and maintained with lacrigel (Europhta) to further ensure good electrical contact. A stainless steel reference electrode to normalize signal output was inserted subcutaneously in the cheek of the mouse and a second needle electrode inserted subcutaneously in the back of the mouse served to ground the signal. Recordings were made from both eyes simultaneously. ${ }^{44}$ ERGs were performed on $n=7$ mice at each age group under normal conditions. ERGs were carried out on $n=10$ mice from two replica experiments involving hyperoxic containment of mice, the second of which carried out as a blind test.

Recording measurements. The light stimulus was provided by a $150 \mathrm{~W}$ xenon lamp in a Ganzfeld stimulator (Multiliner Vision, Jaeger Toennies, Germany). Responses were amplified and filtered ( $1 \mathrm{~Hz}$-low and $300 \mathrm{~Hz}$-high cut off filters) with a 1 channel DC-/AC-amplifier. Following overnight dark-adaptation rod responses were determined to flash intensities between 0.01 and $10 \mathrm{cds} / \mathrm{m}^{2}$. Each scotopic ERG represents the average of five responses from a set of five flashes of stimulation. For recovery experiments bleaching was carried out in the Ganzfeld dome at $3 \mathrm{cds} / \mathrm{m}^{2}$ for 5 -min periods and the scotopic responses recorded using a $0.1 \mathrm{cds} / \mathrm{m}^{2}$ stimulus. To isolate cone responses a 10 -min light saturation at $25 \mathrm{cds} /$ $\mathrm{m}^{2}$ was used to desensitize the rods. ${ }^{45}$ The cone photopic ERGs shown represents the average of 10 responses from 10 consecutive flashes at $10 \mathrm{cds} / \mathrm{m}^{2}$ intensity. The flicker ERG was also used to isolate cone responses at flash frequencies of 10 , 15 and $30 \mathrm{~Hz}$ and $3 \mathrm{cds} / \mathrm{m}^{2}$ intensity.

Data acquisition. For all scotopic recordings, a-wave amplitude was measured from the baseline to the $a$-wave trough and $b$-wave amplitude was measured from the $a$-wave trough to the peak of the $b$ wave. The murine cone ERG has no initial a wave except under the weakest background field, therefore photopic-wave amplitudes were measured from the base-line to the peak of the photopic $b$ wave..$^{45}$ The Naka-Rushton equation ${ }^{45,46}$ was used to determine the sensitivity of the rod response: $\left.V=\left(V_{\max }{ }^{*}\right)^{n}\right) /$ $\left(k^{n}+I^{n}\right) V$ refers to the voltage at intensity $I, V_{\max }$ is the maximum amplitude elicited in the intensity series and the parameter $k$ represents the light intensity required to produce a half-maximal response. The least-square curve fits of scotopic $b$-wave data were carried out using OriginPro version 8 software (Northampton, MA, USA) to calculate parameters of the Naka-Rushton function.

Statistics. Standard $t$-tests were used to determine significance in differences between pairs for morphological data, TBARS analysis and cone counts. The combined coefficients of variation, as computed by the Roche LightCycler 3.5 Software, were used to determine fold range of expression in quantitative RT-PCR data. $R /$ bioconductor was used in the statistical analysis of all microarray data. The Mann-Whitney-Wilcoxon two-sample test was used to compare data sets of ERG measurements. For all experiments data were expressed as the mean \pm the S.E.M. In the figures, different levels of significance are indicated by * if $P<0.05$, ${ }^{\star *} P<0.01$

\section{Conflict of interest}

The authors declare no conflict of interest.

Acknowledgements. We thank Prof Matt Lavail (University of California, San Francisco, CA, USA) for advice regarding ONL measurements and calculations. Jean Bennett and Tonia Rex (University of Philadelphia, PA, USA) for advice during this work. Amandine Langelé and Manuel Simonutti for technical assistance in ERG measurements. Isabelle Renault for technical assistance in the animal facility, Alain Trembleau (UPMC) for electron microscopy, Theo van Veen (University of Lund, Sweden) for the $\mathrm{C} 3 \mathrm{H} \mathrm{rd} 1$ and wt mice. The post-mortem human brain tissues were obtained from NeuroCEB (Paris), thanks to Charles Duyckaerts (ICM). This work was supported by Inserm, the European commission (RETinal Training NETwork), ANR Maladies rares 2006 Grant and FFB USA.

1. O'Reilly M, Chadderton N, Millington-Ward S, Ader M, Farrar GJ, Cronin T et al. RNA interference-mediated suppression and replacement of human rhodopsin in vivo. Am J Hum Genet 2007; 81: 127-135.

2. Cideciyan AV, Aleman TS, Boye SL, Schwartz SB, Hauswirth WW, Kaushal S et al. Human gene therapy for RPE65 isomerase deficiency activates the retinoid cycle of vision but with slow rod kinetics. Proc Natl Acad Sci USA 2008; 105: 15112-15117.

3. Maguire AM, Simonelli F, Pierce EA, Pugh Jr EN, Bennett J, Banfi S et al. Safety and efficacy of gene transfer for Leber's congenital amaurosis. N Engl J Med 2008; 358: 2282-2284. 
4. Bainbridge JW, Smith AJ, Barker SS, Robbie S, Ali RR, Henderson R et al. Effect of gene therapy on visual function in Leber's congenital amaurosis. N Engl J Med 2008; 358 2231-2239.

5. Phelan JK, Bok D. A brief review of retinitis pigmentosa and the identified retinitis pigmentosa genes. Mol Vis 2006; 6: 116-124.

6. Naash MI, Holyfield JG, al-Ubaidi MR, Baehr W. Simulation of human autosomal dominant retinitis pigmentosa in transgenic mice expressing a mutated murine opsin gene. Proc Natl Acad Sci USA 1993; 90: 5499-5503.

7. Goto Y, Peachey NS, Ripps H, Naash Ml. Functional abnormalities in transgenic mice expressing a mutant rhodopsin gene. Invest Ophthalmol Vis Sci 1995; 36: 62-71.

8. Léveillard T, Mohand-Saïd S, Lorentz O, Hicks D, Fintz AC, Clérin E et al. Identification and characterization of rod-derived cone viability factor. Nat Genet 2004; 36: 755-759.

9. Yang Y, Mohand-Said S, Danan A, Simonutti M, Fontaine V, Clerin E et al. Functional cone rescue by RdCVF protein in a dominant model of Retinitis Pigmentosa. Mol Ther 2009; 17 787-795

10. Wang XW, Tan BZ, Sun M, Ho B, Ding JL. Thioredoxin-like 6 protects retinal cell line from photooxidative damage by upregulating NF-kappaB activity. Free Radic Biol Med 2008; 45 : 336-344.

11. Chalmel F, Léveillard T, Jaillard C, Lardenois A, Berdugo N, Morel E et al. Rod-derived cone viability factor-2 is a novel bifunctional-thioredoxin-like protein with therapeutic potential. BMC Mol Biol 2007; 8: e74.

12. Lillig $\mathrm{CH}$, Holmgren A. Thioredoxin and related molecules: from biology to health and disease. Antioxid Redox Signal 2007; 9: 25-47.

13. Wang XW, Liou YC, Ho B, Ding JL. An evolutionarily conserved 16-kDa thioredoxin-related protein is an antioxidant which regulates the NF-kappaB signaling pathway. Free Radic Biol Med 2007; 42: 247-259.

14. Fridlich R, Delalande F, Jaillard C, Lu J, Poidevin L, Cronin T et al. The thioredoxin-like protein RdCVFL interacts with Tau and inhibits its phosphorylation in the retina. Mol Cell Proteomics 2009; 8: 1206-1218.

15. Rattner $A$, Nathans J. The genomic response to retinal disease and injury: evidence for endothelin signaling from photoreceptors to glia. J Neurosci 2005; 25: 4540-4549.

16. Zhang SC, Barclay C, Alexander LA, Geldenhuys L, Porter GA, Casson AG et al Alternative splicing of the FGF antisense gene: differential subcellular localization in human tissues and esophageal adenocarcinoma. J Mol Med 2007; 85: 1215-1228.

17. Yamada H, Yamada E, Ando A, Esumi N, Bora N, Saikia J et al. Fibroblast growth factor-2 decreases hyperoxia-induced photoreceptor cell death in mice. Am J Pathol 2001; 159 1113-1120.

18. Harada T, Harada C, Kohsaka S, Wada E, Yoshida K, Ohno S et al. Microglia-Müller glia cell interactions control neurotrophic factor production during light-induced retinal degeneration. J Neurosci 2002; 22: 9228-9236.

19. Combadière C, Feumi C, Raoul W, Keller N, Rodéro M, Pézard A et al. CX3CR1dependent subretinal microglia cell accumulation is associated with cardinal features of age-related macular degeneration. J Clin Invest 2007; 117: 2758-2762.

20. Punzo $\mathrm{C}$, Cepko $\mathrm{CL}$. Cellular responses to photoreceptor death in the rd1 mouse model of retinal degeneration. Invest Ophthalmol Vis Sci 2007; 48: 849-857.

21. Zarkovic N. 4-Hydroxynonenal as a bioactive marker of pathophysiological processes. Mol Aspects Med 2003; 24: 281-291.

22. Ethen CM, Reilly C, Feng X, Olsen TW, Ferrington DA. Age-related macular degeneration and retinal protein modification by 4-hydroxy-2-nonenal. Invest Ophthalmol Vis Sci 2007; 48: 3469-3479.

23. Yamada H, Yamada E, Hackett SF, Ozaki H, Okamoto N, Campochiaro PA. Hyperoxia causes decreased expression of vascular endothelial growth factor and endothelial cell apoptosis in adult retina. J Cell Physiol 1999; 179: 149-156.

24. Walsh N, Bravo-Neuvo A, Geller S, Stone J. Resistance of photoreceptors in the C57BL/6c2J, C57BL/6J, and BALB/cJ mouse strains to oxygen stress: evidence of an oxygen phenotype. Curr Eye Res 2004; 29: 441-447.
25. Iqbal K, Liu F, Gong CX, Alonso Adel C, Grundke-lqbal I. Mechanisms of tau-induced neurodegeneration. Acta Neuropathol 2009; 118: 53-69.

26. Punzo C, Kornacker K, Cepko CL. Stimulation of the insulin/mTOR pathway delays cone death in a mouse model of retinitis pigmentosa. Nat Neurosci 2009; 12: 44-52.

27. Lahdenranta J, Pasqualini R, Schlingemann RO, Hagedorn M, Stallcup WB, Bucana CD et al. An anti-angiogenic state in mice and humans with retinal photoreceptor cell degeneration. Proc Natl Acad Sci USA 2001; 98: 10368-10373.

28. Mellén MA, de la Rosa EJ, Boya $P$. The autophagic machinery is necessary for removal of cell corpses from the developing retinal neuroepithelium. Cell Death Differ 2008; 15 $1279-1290$.

29. Lohr HR, Kuntchithapautham K, Sharma AK, Rohrer B. Multiple, parallel cellular suicide mechanisms participate in photoreceptor cell death. Exp Eye Res 2006; 83: 380-389.

30. Yamada T, Iwasaki Y, Nagata K, Fushiki S, Nakamura H, Marunaka Y et al. Thioredoxin-1 protects against hyperoxia-induced apoptosis in cells of the alveolar walls. Pulm Pharmacol Ther 2006; 20: 650-659.

31. Funato $Y$, Michiue T, Asashima M, Miki H. The thioredoxin-related redox-regulating protein nucleoredoxin inhibits Wnt-beta-catenin signaling through dishevelled. Nat Cell Biol 2006; 8: $501-850$.

32. Schwenk F, Baron U, Rajewsky K. A cre-transgenic mouse strain for the ubiquitous deletion of loxP-flanked gene segments including deletion in germ cells. Nucleic Acids Res 1995; 23: 5080-5081.

33. Mohand-Said S, Deudon-Combe A, Hicks D, Simonutti M, Forster V, Fintz AC et al. Normal retina releases a diffusible factor stimulating cone survival in the retinal degeneration mouse. Proc Natl Acad Sci USA 1998; 95: 8357-8362.

34. Blanks JC, Johnson LV. Selective lectin binding of the developing mouse retina. J Comp Neurol 1983; 221: 31-41.

35. Hicks D, Barnstable CJ. Different rhodopsin monoclonal antibodies reveal different binding patterns on developing and adult rat retina. $J$ Histochem Cytochem 1987; 35 1317-1328.

36. Dong A, Shen J, Krause M, Hackett SF, Campochiaro PA. Increased expression of glial cell line-derived neurotrophic factor protects against oxidative damage-induced retinal degeneration. J Neurochem 2007; 103: 1041-1052.

37. Chang $\mathrm{E}$, Kuret J. Detection and quantification of tau aggregation using a membrane filter assay. Anal Biochem 2008; 373: 330-336.

38. Faktorovich EG, Steinberg RH, Yasumura D, Matthes MT, LaVail MM. Basic fibroblas growth factor and local injury protects photoreceptors from light damage in the rat J Neurosci 1992; 12: 3554-3567.

39. Andrews NC, Faller DV. A rapid micropreparation technique for extraction of DNA-binding proteins from limiting numbers of mammalian cells. Nucleic Acids Res 1991; 19: 2499

40. Glisin V, Crkvenjakov R, Byus C. Ribonucleic acid isolated by cesium chloride centrifugation. Biochemistry 1974; 13: 2633-2637.

41. Raffelsberger $W$, Krause $Y$, Moulinier L, Kieffer D, Morand AL, Brino $L$ et al RReportGenerator: automatic reports from routine statistical analysis using $R$ Bioinformatics 2008; 24: 276-278.

42. Ploner A, Calza S, Gusnanto A, Pawitan Y. Multidimensional local false discovery rate fo microarray studies. Bioinformatics 2006; 22: 556-565.

43. Wicker N, Dembele D, Raffelsberger W, Poch O. Density of points clustering, application to transcriptomic data analysis. Nucleic Acids Res 2002; 30: 3992-4000.

44. Frasson M, Sahel JA, Fabre M, Simonutti M, Dreyfus H, Picaud S. Retinitis pigmentosa: rod photoreceptor rescue by a calcium-channel blocker in the rd mouse. Nat Med 1999; 5 1183-1187.

45. Peachey NS, Goto Y, al-Ubaidi MR, Naash MI. Properties of the mouse cone-mediated electroretinogram during light adaptation. Neurosci Lett 1993; 162: 9-11.

46. Ekesten B, Gouras P, Moschos M. Cone properties of the light-adapted murine ERG. Doc Ophthalmol 1998; 97: 23-31. 